\title{
Sponge City Development and Technology Research
}

\author{
Guangdi Zhang ${ }^{\text {a, }}{ }^{*}$, Fan Yang ${ }^{b}$, Wei Liu and $\mathrm{Na} \mathrm{Ni}$
}

The NO.203 Institute of the Second Academy of China Aerospace Science \& Industry Corp, Beijing 100854, China.

a, *18513713080@126.com, b 499826187@qq.com

\begin{abstract}
Sponge City means that the city can be like a sponge. It has good "elasticity" in adapting to environmental changes and coping with natural disasters. When it rains, it absorbs water, stores water, seeps water, cleans water, and releases the stored water when needed. And use it. Sponge city construction should follow the principle of ecological priority, combine natural and artificial measures, maximize the accumulation, penetration and purification of rainwater in urban areas and promote the utilization of rainwater resources on the premise of ensuring urban drainage and flood control. And ecological protection. In the process of sponge city construction, the systemic nature of natural precipitation, surface water and groundwater should be coordinated, and all aspects of water recycling, such as water supply and drainage, should be coordinated, and its complexity and longterm nature should be considered.
\end{abstract}

Keywords: Sponge City; Penetration; Storage; Purification.

\section{Introduction}

To build a sponge city, there must be a "sponge body". The city "sponge body" includes water systems such as rivers, lakes, ponds, and other urban facilities such as green spaces, gardens, and permeable road surfaces. The rainwater is infiltrated, depleted, purified and reused by these "sponge bodies".[1]Finally, the remaining part of the runoff passes through the pipe network and the pumping station, which can effectively raise the standard of the urban drainage system and reduce the pressure on the city.

Sponge City can give full play to the effects of urban green space, roads, water systems, etc. on rainwater absorption, infiltration and slow release, effectively alleviate urban floods, reduce urban runoff pollution load, save water resources, and protect and improve urban ecological environment.

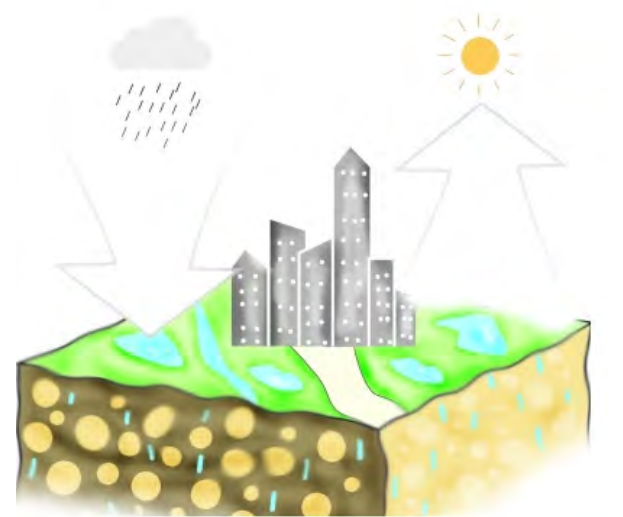

Fig. 1 Schematic diagram of sponge city

\section{Sponge City Construction Requirements}

The so-called sponge city is to give full play to the accumulation of the original topography and landform on rainfall, give full play to the natural underlying surface and ecological background to penetrate the rainwater, and give full play to the natural purification effect of vegetation, soil and wetland on the water quality, so that the city image Like the "sponge", it has the function of absorbing and releasing rainwater, and can flexibly adapt to environmental changes and cope with natural disasters[2]. In the urban development and construction, strengthen planning and construction control, 
through the source emission reduction, process control, system governance, take measures such as roof greening, permeable pavement, recessed green space, rainwater collection and utilization facilities, etc., to make buildings and communities, roads and squares Parks, green spaces, and water systems have the functions of absorption, storage, and slow release of rainwater, effectively controlling the runoff of rainwater, so that ordinary people can truly feel that "small rain does not accumulate water, heavy rain does not guilty, water bodies are not black and smelly, and heat islands are alleviated." Effective.

The key to building a sponge city is to continuously expand the scale of the "sponge body" and improve its quality. The original "sponge body" should be effectively protected. The damaged "sponge body" should also be gradually restored by comprehensive use of physical, biological and ecological means, and maintain a certain proportion of ecological space. If conditions permit, a certain size of "sponge body" should also be built. The construction of sponge cities should be based on the construction of urban buildings, communities, roads, green spaces and squares. For example, let the roof of the city be "green". The "green" roof can also save energy and reduce emissions while mitigating the rain.

\section{Sponge City Technology Research}

\subsection{Penetration}

Because the city's underlying surface is too hard and cement is everywhere, it changes the original natural ecological background and hydrological characteristics. Therefore, it is necessary to strengthen the natural penetration and put the penetration first. The advantage is that it can avoid surface runoff, reduce the accumulation of cement ground and road surface into the pipe network, at the same time, conserve the groundwater and supplement the groundwater, and can also purify the water quality through the soil and improve the urban microclimate. The methods of penetrating rainwater are various, mainly to change various pavements, ground pavement materials, renovate the roof greening, adjust the vertical direction of the green space, leave the rainwater from the source and then "seep" it.

Permeable paving, permeable concrete paving and permeable concrete paving, inlaid bricks, pebbles in garden paving, gravel paving, etc. are also infiltration paving. When the land permeability is limited, drainage pipes or drainage boards shall be provided in the permeable base layer of the permeable pavement.

\subsection{Storage}

The most important thing to save is to keep the rain, to respect the natural topography and make the rainfall naturally scattered. Now that the artificial construction has destroyed the natural topography, the water is collected in one place in a short time, and the guilt is formed. So save the rain to save and peak. At present, there are no fixed standards and requirements for the water storage in the sponge city. There are various underground water storage modes. There are two general forms of use: underground reservoirs and plastic modules. Common ways of storing water are underground reservoirs and water storage modules. The water storage module is a new type of product that can be used to store water but does not take up space; it has superior pressure bearing capacity; $95 \%$ of the hollow space can achieve more efficient water storage. Water storage and drainage can be done with tarpaulin or geotextile. At the same time, it is necessary to set the inlet pipe, outlet pipe, pump position and inspection well in the structure.

\subsection{Stay}

The main role of detention is to delay the formation of rainwater runoff in a short period of time. For example, through micro-topography, let the rain slowly gather in one place and use time to change space. By "stagnation", the peak of runoff can be delayed. The specific forms are summarized into three types: rain garden, ecological detention pool, infiltration pool, and constructed wetland. 
Rain garden refers to a low-lying area where trees or shrubs are planted in garden green spaces, covered by bark or ground cover. It replenishes groundwater by reducing the stagnation of rainwater and reduces the flooding of storm surface runoff. It also reduces pollution through processes such as adsorption, degradation, ion exchange and volatilization. Among them, the shallow pit can accumulate a certain amount of rainwater, delaying the accumulation of rainwater, and the soil can increase the rainwater infiltration and alleviate the phenomenon of surface water accumulation. The accumulated rainwater can be used by plants to reduce the amount of irrigation water in the green space.
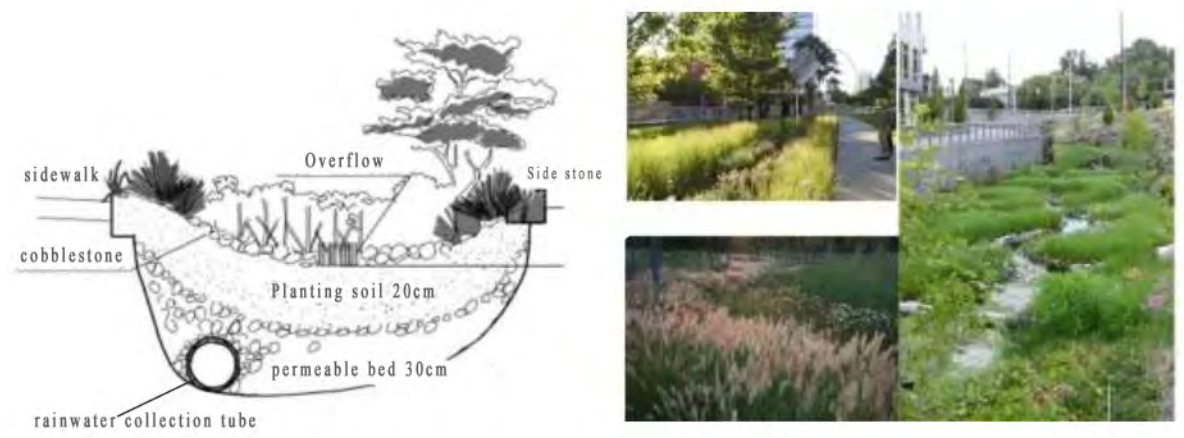

Fig. 2 Detention to form runoff

\subsection{Purification}

Through the infiltration of soil, through the vegetation, green space system, water body, etc., can purify the water quality. Therefore, it should be stored, purified, and reused in the city. The rainwater purification system sets different purification systems according to different regional environments. According to the current situation of the city, the regional environment can be roughly divided into three categories: rainwater collection and purification in residential areas, rainwater collection and purification in industrial areas, and rainwater collection and purification in municipal public areas. According to the three regional environments, different rainwater purification links can be set up, and the more familiar purification process at this stage is divided into three parts: soil percolation purification, artificial wetland purification, and biological treatment.

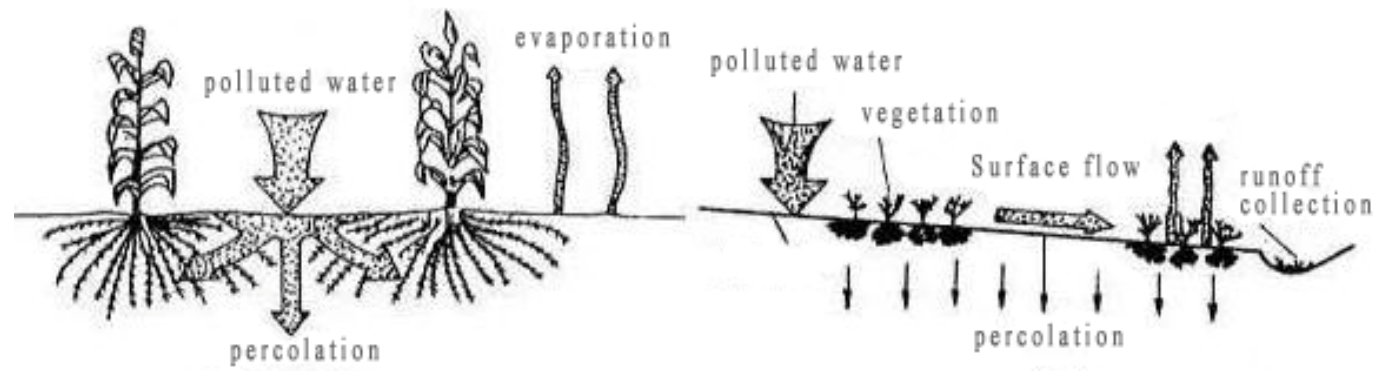

Fig. 3 Slow percolation

\subsection{Drain}

Drainage is the combination of urban vertical and engineering facilities, drainage and flood control facilities combined with natural water systems, ground drainage and underground rainwater drainage channels to achieve general emissions and excessive discharge of rainwater, to avoid catastrophes and other disasters. Some cities are guilty because of excessive rainfall. This requires manual measures to drain the rainwater.

When the peak of the rain is too large, the ground drainage and the underground rainwater pipe can be combined to achieve the discharge of general and excessive rainwater, and avoid disasters such as guilt. Part of the rainwater that has been stored after rainwater gardens, ecological detention 
areas, and infiltration ponds is used for greening irrigation and daily life. Some of them are replenished with groundwater through infiltration, and the excess is discharged into the river through the municipal pipe network. It not only reduces the chance of water accumulation when the peak value of rain is too high, but also reduces the direct pollution of the water source in the first time.

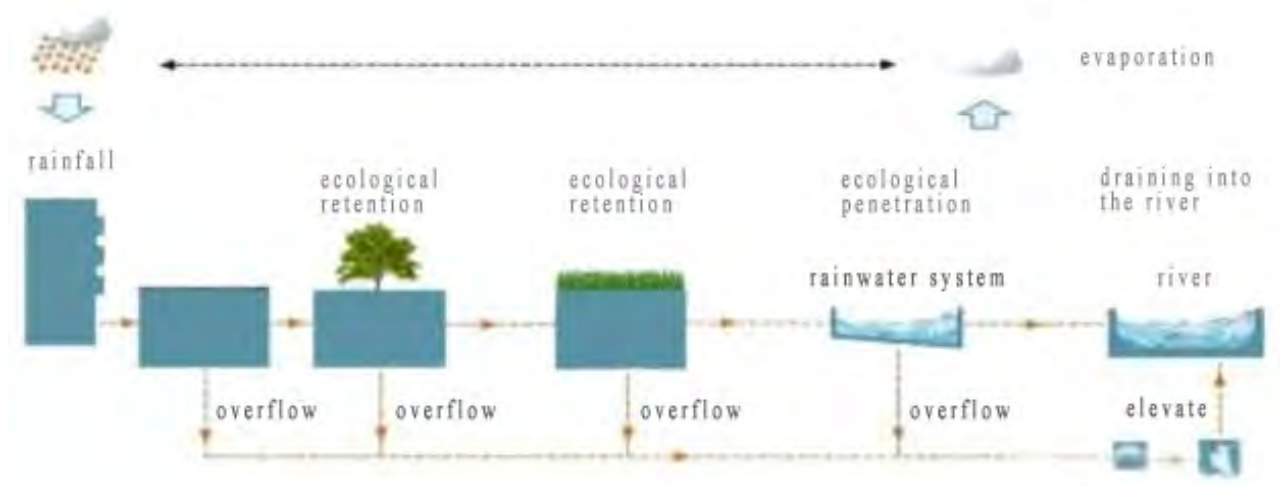

Fig. 4 drainage process diagram

\section{Summary}

Towns are the most important source of water pollution[3]. Through the construction of sponge cities, the city has become the main battlefield for dealing with water pollution, and it is the place to solve water shortage. Creating a sponge city theory, norms and standards with Chinese characteristics has a long way to go. The Ministry of Housing and Urban-Rural Development has issued a technical guide for the construction of sponge cities, but this is far from enough. Everyone needs to constantly explore and correct in time. Sponge City (Low Impact Development) Planning and Smart Water is the two major systems projects that coordinate the effective operation of each unit in Sponge City. If the sponge city planning is "pushing", the sponge wisdom is "pull". "One push and one pull" can effectively coordinate the whole sponge system, neither waste nor information islands. Therefore, the two systems of "one push and one pull" are very important system designs. The sponge city system should be divided into four subsystems from large to small, namely, region, city, community, and architecture. The four-level system has different emphasis on low-impact development, and it is necessary to promote system innovation in combination.

\section{References}

[1]. Qiu Baoxing. The Connotation, Ways and Prospects of Sponge City (LID). China Survey and Design, 2015(7): 11-18.

[2]. Y Yang, G Lin, et al. A Review on Sponge City. (South Architecture),2015.

[3]. D Zhou.The Application of the Sponge City in Modern City Construction. (Journal of Anhui Agricultural Sciences), 2015. 